This item was submitted to Loughborough's Research Repository by the author.

Items in Figshare are protected by copyright, with all rights reserved, unless otherwise indicated.

\title{
The biophysical and physiological basis for mitigated elevations in heart rate with electric fan use in extreme heat and humidity.
}

PLEASE CITE THE PUBLISHED VERSION

http://dx.doi.org/10.1007/s00484-016-1213-0

PUBLISHER

Springer / ( I ISB

VERSION

AM (Accepted Manuscript)

\section{PUBLISHER STATEMENT}

This work is made available according to the conditions of the Creative Commons Attribution-NonCommercialNoDerivatives 4.0 International (CC BY-NC-ND 4.0) licence. Full details of this licence are available at: https://creativecommons.org/licenses/by-nc-nd/4.0/

\section{LICENCE}

CC BY-NC-ND 4.0

\section{REPOSITORY RECORD}

Ravanelli, Nicholas M., Danial Gagnon, Simon Hodder, George Havenith, and Oliver E. Jay. 2019. "The Biophysical and Physiological Basis for Mitigated Elevations in Heart Rate with Electric Fan Use in Extreme Heat and Humidity.". figshare. https://hdl.handle.net/2134/22407. 
The biophysical and physiological basis for mitigated elevations in heart rate with electric fan use in extreme heat and humidity

5 Nicholas M. Ravanelli ${ }^{1,4}$, Daniel Gagnon ${ }^{2}$, Simon G. Hodder $^{3}$, George Havenith $^{3}$ and Ollie Jay ${ }^{4,5} \bowtie$

${ }^{1}$ School of Human Kinetics, University of Ottawa, 200 Lees Ave, Ottawa, CANADA, K1N 6N5

$9{ }^{2}$ Cardiovascular Prevention and Rehabilitation Centre (ÉPIC), Montreal Heart Institute Research Centre and Department of Molecular and Integrative Physiology, Faculty of Medicine, Université de Montréal, CANADA.

${ }^{3}$ Environmental Ergonomics Research Centre, Loughborough Design School, Loughborough University, Leics, UNITED KINGDOM, LE11 3TU

${ }^{4}$ Thermal Ergonomics Laboratory, Faculty of Health Sciences, University of Sydney, NSW, AUSTRALIA

${ }^{5}$ Charles Perkins Centre, University of Sydney, NSW, AUSTRALIA

Running Title: Electric fan use during heat waves

Keywords: heat waves, cardiovascular strain, thermoregulation, sweating

Address for correspondence:

Dr. O. Jay $\bowtie$

Thermal Ergonomics Laboratory, Faculty of Health Sciences, University of Sydney, NSW 2141. Australia + 61 (2) 935-19328

e-mail: ollie.jay@sydney.edu.au 


\section{ABSTRACT}

37 Electric fan use in extreme heat wave conditions has been thought to be disadvantageous because

38 it might accelerate heat gain to the body via convection. However, it has been recently shown

39 that fan use delays increases in heart rate even at high temperatures $\left(42^{\circ} \mathrm{C}\right)$ in young adults. We

40 here assess the biophysical and physiological mechanisms underlying the apparently beneficial

41 effects of fan use. Eight males $\left(24 \pm 3 \mathrm{y} ; 80.7 \pm 11.7 \mathrm{~kg} ; 2.0 \pm 0.1 \mathrm{~m}^{2}\right)$ rested at either $36^{\circ} \mathrm{C}$ or $42^{\circ} \mathrm{C}$,

42 with (F) or without (NF) electric fan use $(4.2 \mathrm{~m} / \mathrm{s})$ for $120 \mathrm{~min}$ while humidity increased every

$437.5 \mathrm{~min}$ by $0.3 \mathrm{kPa}$ from a baseline value of $1.6 \mathrm{kPa}$. Heart rate (HR), local sweat rate (LSR),

44 cutaneous vascular conductance $(\mathrm{CVC})$, core and mean skin temperatures, and the combined

45 convective/radiative heat loss $(\mathrm{C}+\mathrm{R})$, evaporative heat balance requirements $\left(\mathrm{E}_{\text {req }}\right)$ and maximum

46 evaporative potential $\left(\mathrm{E}_{\max }\right)$ were assessed. $\mathrm{C}+\mathrm{R}$ was greater with fan use at $36^{\circ} \mathrm{C}(\mathrm{F}: 8 \pm 6, \mathrm{NF}$ :

$\left.472 \pm 2 \mathrm{~W} \cdot \mathrm{m}^{-2} ; \mathrm{P}=0.04\right)$ and more negative (greater dry heat gain) with fan use at $42^{\circ} \mathrm{C}(\mathrm{F}:-78 \pm 4$,

$\left.48 \mathrm{NF}:-27 \pm 2 \mathrm{~W} \cdot \mathrm{m}^{-2} ; \mathrm{P}<0.01\right)$. Consequently $\mathrm{E}_{\text {req }}$ was lower at $36^{\circ} \mathrm{C}\left(\mathrm{F}: 38 \pm 16, \mathrm{NF}: 45 \pm 3 \mathrm{~W} \cdot \mathrm{m}^{-2}\right.$;

$49 \mathrm{P}=0.04)$ and greater at $42^{\circ} \mathrm{C}\left(\mathrm{F}: 125 \pm 1, \mathrm{NF}: 74 \pm 3 \mathrm{~W} \cdot \mathrm{m}^{-2} ; \mathrm{P}<0.01\right)$ with fan use. However, fan use

50 resulted in a greater $\mathrm{E}_{\max }$ at baseline humidity at both $36^{\circ} \mathrm{C}\left(\mathrm{F}: 343 \pm 10, \mathrm{NF}: 153 \pm 5 \mathrm{~W} \cdot \mathrm{m}^{-2}\right.$;

$51 \mathrm{P}<0.01)$ and $42^{\circ} \mathrm{C}\left(\mathrm{F}: 376 \pm 13, \mathrm{NF}: 161 \pm 4 \mathrm{~W} \cdot \mathrm{m}^{-2} ; \mathrm{P}<0.01\right)$ and throughout the incremental

52 increases in humidity. Within the humidity range that a rise in HR was prevented by fan use but

53 not without a fan, LSR was higher in NF at both $36^{\circ} \mathrm{C}(\mathrm{P}=0.04)$ and $42^{\circ} \mathrm{C}(\mathrm{P}=0.05)$, and skin

54 temperature was higher in $\mathrm{NF}$ at $42^{\circ} \mathrm{C}(\mathrm{P}=0.05)$, but no differences in $\mathrm{CVC}$ or core temperatures

55 were observed (all $\mathrm{P}>0.05$ ). These results suggest that the delayed increase in heart rate with fan

56 use during extreme heat and humidity is associated with improved evaporative efficiency. 


\section{INTRODUCTION}

Over the past 20 years, heat waves - characterized by extended bouts of extreme heat and

60 humidity - have led to high levels of excess morbidity and mortality in the United States

61 (Whitman et al. 1997), Europe (Fouillet et al. 2006), Australia (Nitschke et al. 2011), and most

62 recently India and Pakistan (Lancet 2015). Cardiovascular events are consistently identified as an

63 underlying cause of heat-related mortality and morbidity (Bouchama et al. 2007; Hajat et al.

64 2010), with those who do not have access to air conditioning being particularly vulnerable.

65 Moreover, the high electricity requirements associated with widespread air conditioning use by

66 the majority of households in urban areas during heat waves have in some cases led to massive

67 power failures (Luber and McGeehin 2008), and a consequent surge in morbidity and mortality

68 rates (Schuman 1972; Hartz et al. 2012). It is therefore evident that affordable and energy

69 efficient cooling strategies (Kravchenko et al. 2013) are urgently needed to mitigate

70 cardiovascular strain during heat waves.

71 Electric fans provide a simple cooling intervention at a fraction of the price and energy

72 requirement of modern air conditioning (Gupta et al. 2012; Salamanca et al. 2014). However,

73 current heat management guidelines from public health agencies such as the World Health

74 Organization, United States Environmental Protection Agency, and The Centers for Disease

75 Control and Prevention typically advise against fan use at air temperatures above 35 to $37^{\circ} \mathrm{C}$ as

76 they are thought to, at best, be ineffective (Wolfe 2003; CDC 2004), and at worst, exacerbate

77 physiological strain and the risk of heat illness and dehydration (Wolfe 2003; Matthies et al.

78 2008; Victorian Government Department of Health 2013). We recently demonstrated that

79 electric fan use at air temperatures up to $42^{\circ} \mathrm{C}$ delays heat-induced elevations in heart rate in

80 young healthy males (Ravanelli et al. 2015). However, the underlying physiological and 
81 biophysical mechanisms for the protective effect of electric fans at high air temperatures and

82 humidity were not determined.

83 When ambient temperature exceeds skin temperature, which in a hot environment will

84 typically be $\sim 35^{\circ} \mathrm{C}$ (Gagge et al. 1937), heat will be gained via convection. With fan use, this

85 environmental heat load will be added to the body at a faster rate. However, fan use favours

86 elevated rates of sweat evaporation. Importantly, increased levels of sweat evaporation with fan

87 use can be achieved without the need for greater sweat production through improvements in

88 evaporative efficiency - the amount of sweat that evaporates relative to the amount produced

89 (Adams et al. 1992). In contrast, not using a fan would lead to decrements in evaporative

90 efficiency and therefore greater sweat rates to overcome compromised sweat evaporation

91 (Candas et al. 1979b). Since greater sweat rates are generally accompanied by greater cutaneous

92 vasodilation (Wingo et al. 2010; Smith et al. 2013), it is possible that the delayed increase in

93 heart rate with fan use during passive heat exposure is associated with less peripheral

94 vasodilation and therefore less of a need for cardiac output to increase in order to maintain blood

95 pressure.

96 The purpose of the present study was to i) evaluate how changes in physiological heat

97 loss responses and human heat balance are altered by electric fan use during simulated extreme

98 heat wave conditions; and ii) identify how fan use previously resulted in a lower heart rate

99 (Ravanelli et al. 2015) at air temperatures equal to $\left(36^{\circ} \mathrm{C}\right)$, and far exceeding $\left(42^{\circ} \mathrm{C}\right)$ the limits

100 for fan use presently stated in public health recommendations (CDC 2004; WHO 2009). It was

101 hypothesized that improved sweat evaporation with fan use outweighs greater convective heat

102 gain, leading to a lower requirement for skin blood flow and sweat production. 


\section{METHODS}

105

106

107

108

109

110

111 University of Ottawa Research Ethics Board, and conformed to the guidelines set forth in the

1121964 Declaration of Helsinki. All participants provided written informed consent prior to their

113 participation in the study. Participants were instructed to avoid vigorous exercise or physical

114 activity 24 hours prior, refrain from alcohol 12 hours prior, eat a light meal, and avoid any

115 caffeinated beverages at least 6 hours prior to testing. The preliminary visit consisted of

116 providing informed consent and anthropometric measurements (weight and height) to estimate 117 body surface area (DuBois and Dubois 1916).

\section{Instrumentation} was estimated to be located at a region nearest the left ventricle (Mekjavic and Rempel 1990).

124 Skin temperature was measured using four thermistors (Concept Engineering, Old Saybrook, CT, 125 USA) which were secured to the skin using surgical tape (Transpore ${ }^{\circledR}, 3 \mathrm{M}$, London, ON). Mean 126 skin temperature was calculated as the weighted average of four sites using the formula reported 
127 by Ramanathan (1964): chest $30 \%$, triceps $30 \%$, thigh $20 \%$, and calf $20 \%$. Temperature

128 measurements were sampled every $5 \mathrm{~s}$ (NI cDAQ-91722 module, National Instruments, Austin,

129 TX) and displayed in real-time on a desktop computer using customized LabView software

130 (v7.0, National Instruments, Austin, TX).

Heart rate was measured using cardio-recorder (Polar RS 800, Polar electro Oy,

132 Kempele, Finland) and coded transmitter (Polar wearlink T31 coded, Polar electro Oy, Kempele,

133 Finland) which recorded every 5 seconds. The recording was downloaded to a desktop computer

134 using the manufacturer's software (Polar ProTrainer Versions 5.40.172, Kempele, Finland) and

135 averaged every minute. Systolic and diastolic blood pressures were measured using an automated

136 cuff (E-Sphyg II 9002, American Diagnostic Corporation, Hauppauge, NY, USA) at baseline,

137 and at the end of each humidity stage during the ramp protocol. Mean arterial pressure was

138 subsequently calculated as:

$139(1 / 3 \times$ systolic blood pressure $)+(2 / 3 \times$ diastolic blood pressure $)[\mathrm{mmHg}]$

140 Skin blood flow was measured using Laser Doppler Flowmetry probes (Small Angled

141 Thermostatic Probe \#457, Perimed, Järfälla, Sweden) placed on the chest and forearm. Skin

142 blood flow perfusion units were displayed by the Laser Doppler Perfusion Monitor (Periflux

143 System 5000, Perimed, Järfälla, Sweden) and simultaneously recorded at a sampling rate of 5

144 seconds by the manufacturers software (Perisoft for Windows Version 2.5.5, Perimed, Järfälla,

145 Sweden). Skin blood flow was averaged between recordings from the chest and forearm and

146 expressed as i) absolute values and ii) cutaneous vascular conductance, which was derived as the

147 quotient of perfusion units and mean arterial pressure. 
Local sweat rates of the chest and forearm were measured using ventilated sweat

149 capsules. Anhydrous air was supplied through each $4.1-\mathrm{cm}^{2}$ capsule at a rate of $1.2 \mathrm{~L} / \mathrm{min}$ (chest)

150 and $1.4 \mathrm{~L} / \mathrm{min}$ (forearm). Capsules were secured to the skin using surgical tape. The temperature

151 and humidity of the air leaving both capsules were measured by individually factory calibrated

152 capacitance hygrometers (HMT333, Vaisala, Vantaa, Finland). Local sweat rates were calculated

153 as the product of flow rate and effluent absolute humidity, and expressed relative to the amount

154 of skin surface covered by the capsule $\left(\mathrm{mg} / \mathrm{cm}^{2} / \mathrm{min}\right)$. Local sweat rate was expressed as the 155 average between chest and forearm.

\section{Experimental protocol}

All trials were performed in a climatic chamber that precisely regulated ambient air

158 temperature and absolute humidity, situated at the Thermal Ergonomics Laboratory at the

159 University of Ottawa in Canada. During the fan trials, an 18" diameter mechanical fan

160 (Whirlpool, Benton Harbor, MI, USA) was set at full speed and placed $1.0 \mathrm{~m}$ directly in front of

161 the participant. The mean whole body air velocity $(4.2 \mathrm{~m} / \mathrm{s})$ generated by the fan was derived

162 from calculations of the convective heat transfer coefficient $\left(h_{c}-\right.$ see equation 4$)$ using

163 measurements of convective heat loss (see equation 3 ) in a $15^{\circ} \mathrm{C}$ environment using a 34 zone

164 thermal manikin (NEWTON; Measurement Technology Northwest, Seattle, USA) at the

165 Environmental Ergonomics Centre at Loughborough University, UK. The four experimental 166 trials were i) $36^{\circ} \mathrm{C}$ with fan $(36 \mathrm{~F})$; ii) $36^{\circ} \mathrm{C}$ with no fan $(36 \mathrm{NF})$; iii) $42^{\circ} \mathrm{C}$ with fan (42F); and iv)

$16742^{\circ} \mathrm{C}$ with no fan (42NF). The experimental trials were presented in a balanced order determined 168 using a Latin square design. All trials were separated by at least $48 \mathrm{~h}$. Upon arrival at the 169 laboratory, participants provided a urine sample to ensure euhydration and similar hydration 170 states between trials by measuring urine specific gravity with a refractometer (Reichert TS 400, 
171 Depew, NY). All urine specific gravity measurements were lower than 1.025 (Kenefick and

172 Cheuvront 2012) and were similar between experimental trials for each person $( \pm 0.002)$. Each

173 participant wore a standardized t-shirt and shorts and sat on a plastic chair that covered part of

174 their back and upper rear thigh. The dry insulation (with fan: 0.04 clo; without fan: 0.10 clo) and

175 evaporative resistance $\left(0.01 \mathrm{~m}^{2} \mathrm{kPa} / \mathrm{W}\right)$ of this standardized ensemble was measured using a

176 thermal manikin at Loughborough University, UK. During the $36 \mathrm{NF}$ and $42 \mathrm{NF}$ trials,

177 participants sat behind a $122 \mathrm{~cm}$ high barrier to ensure still $(<0.1 \mathrm{~m} / \mathrm{s})$ air flow around them.

178 Throughout all trials, ambient air velocity was measured using a hot wire anemometer

179 (VelociCalc 9535, TSI Inc, Shoreview MN, USA) positioned $\sim 20 \mathrm{~cm}$ anterior to the participants 180 torso.

Each trial began with the participant entering the climatic chamber regulated at a 182 temperature of either $36^{\circ} \mathrm{C}$ or $42^{\circ} \mathrm{C}$, and an ambient vapor pressure of $1.6 \mathrm{kPa}$, and sitting quietly 183 for $45 \mathrm{~min}$. An initial body mass measurement was then taken using a platform scale (Combics 2 , 184 Sartorius, Mississauga, ON, Canada). Following a further $20 \mathrm{~min}$ at a vapor pressure of $1.6 \mathrm{kPa}$, 185 vapor pressure was increased in a step-wise fashion by $0.3 \mathrm{kPa}$ every 7.5 minutes (Kenney et al. 1861993 ) until $5.6 \mathrm{kPa}$, at which point the participant's body mass was once again measured and a 187 urine sample was obtained. The duration of each trial (excluding the $45-\mathrm{min}$ baseline rest) was $188120 \mathrm{~min}$. Table 1 illustrates the ambient temperature and absolute humidity for each stepwise 189 increase in humidity.

\section{Partitional Calorimetry}

191 Heat balance was estimated using partitional calorimetry and parameters are presented as 192 the mean values for each condition. Metabolic heat production $\left(\mathrm{H}_{\text {prod }}\right)$ was not measured and was 193 assumed to be $1.2 \mathrm{~W} / \mathrm{kg}$ of total body based on the following equation: 
$194 H_{\text {prod }}=\mathrm{VO}_{2} \frac{\left(\left(\frac{\mathrm{RER}-0.7}{0.3}\right) \mathrm{e}_{\mathrm{c}}\right)+\left(\left(\frac{1.0-\mathrm{RER}}{0.3}\right) \mathrm{e}_{\mathrm{f}}\right)}{60 \cdot \mathrm{A}_{\mathrm{D}}} \cdot 1000\left[\mathrm{~W} / \mathrm{m}^{2}\right]$

196 Where oxygen consumption $\left(\mathrm{VO}_{2}\right)$ was estimated as $3.5 \mathrm{ml} / \mathrm{kg} / \mathrm{min}$, the respiratory exchange 197 ratio (RER) was assumed to be $0.85, \mathrm{e}_{\mathrm{c}}$ is the caloric equivalent per liter of oxygen for the 198 oxidation of carbohydrates $\left(21.13 \mathrm{~kJ}\right.$ per $\mathrm{L}$ of $\mathrm{O}_{2}$ consumed $), \mathrm{e}_{\mathrm{f}}$ is the caloric equivalent per liter 199 of oxygen for the oxidation of lipids (19.62 kJ per $\mathrm{L}$ of $\mathrm{O}_{2}$ consumed).

200 Convective heat exchange from the skin, $C$, was calculated as (Kerslake, 1972):

$201 C=\mathrm{h}_{\mathrm{c}} \cdot\left(\mathrm{T}_{\mathrm{sk}}-\mathrm{T}_{\mathrm{a}}\right)\left[\mathrm{W} / \mathrm{m}^{2}\right]$

202 Where: $h_{c}$ is the convective heat transfer coefficient for an individual facing an air velocity 203 (Mitchell 1974):

$204 \mathrm{~h}_{\mathrm{c}}=8.3 \cdot \mathrm{v}^{0.6}\left[\mathrm{~W} / \mathrm{m}^{2} / \mathrm{K}\right]$

205 Where: $v$ is mean air velocity derived using a thermal manikin $(4.2 \mathrm{~m} / \mathrm{s})$. During the $36 \mathrm{NF}$ and $20642 \mathrm{NF}$ trials air velocity was less than $0.2 \mathrm{~m} / \mathrm{s}$ and $\mathrm{h}_{\mathrm{c}}$ was assumed to be $3.1 \mathrm{~W} / \mathrm{m}^{2} / \mathrm{K}$ (Parsons 207 2002)

208 Radiant heat transfer (R) was estimated by:

$209 R=\mathrm{h}_{\mathrm{r}} \cdot\left(\mathrm{T}_{\mathrm{sk}}-\mathrm{T}_{\mathrm{r}}\right)\left[\mathrm{W} / \mathrm{m}^{2}\right]$

210 Where: $\mathrm{h}_{\mathrm{r}}$ (radiant heat transfer coefficient) in $\mathrm{W} \cdot \mathrm{m}^{-2} \cdot \mathrm{K}^{-1}$ is estimated using the following:

$211 \mathrm{~h}_{\mathrm{r}}=\varepsilon \cdot 4 \sigma \cdot\left(\mathrm{A}_{\mathrm{r}} / \mathrm{A}_{\mathrm{D}}\right) \cdot\left(\left(\mathrm{T}_{\mathrm{sk}}+\mathrm{T}_{\mathrm{r}}\right) / 2+273.15\right)^{3}\left[\mathrm{~W} / \mathrm{m}^{2} / \mathrm{K}\right]$ 
212 Where: $\varepsilon$ is the area weighted emissivity of the body surface $(0.95), \sigma$ is the Stefan-Boltzmann 213 constant $\left(5.67 \times 10^{-8} \mathrm{~W} / \mathrm{m}^{2} / \mathrm{K}^{4}\right), \mathrm{A}_{\mathrm{r}} / \mathrm{A}_{\mathrm{D}}$ is the effective radiative surface area (ND) which can be

214 estimated as 0.70 for a seated person (Fanger 1967), and $T_{s k}+T_{r}$ is the sum of the mean skin 215 temperature and mean radiant temperature $\left({ }^{\circ} \mathrm{C}\right)$, assumed to be equivalent to $\mathrm{T}_{\mathrm{a}}\left({ }^{\circ} \mathrm{C}\right)$.

216 Respiratory heat loss was estimated using the following:

$217 E_{\text {res }}+C_{\text {res }}=0.0173 \cdot\left(H_{\text {prod }}\right) \cdot\left(5.87-\mathrm{P}_{\mathrm{a}}\right)+0.0014 \cdot\left(H_{\text {prod }}\right) \cdot\left(34-\mathrm{T}_{\mathrm{a}}\right)\left[\mathrm{W} / \mathrm{m}^{2}\right]$

218 The evaporative requirement to maintain heat balance $\left(E_{r e q}\right)$ in $W / \mathrm{m}^{2}$ was estimated by 219 rearranging the conceptual heat balance equation:

$220 \quad E_{r e q}=\mathrm{H}_{\text {prod }}-\left(\mathrm{C}+\mathrm{R}+\mathrm{C}_{\mathrm{res}}+\mathrm{E}_{\mathrm{res}}\right)\left[\mathrm{W} / \mathrm{m}^{2}\right]$

221 Required skin wettedness $\left(\omega_{\text {req }}\right)$, defined by Gagge (1937), was estimated as:

$222 \omega_{r e q}=E_{r e q} / E_{\max }[\mathrm{ND}]$

223 Where: $E_{\max }$ is the theoretical maximum rate of evaporation in the prevailing climate when $100 \%$

224 of the skin surface is saturated in sweat, and can be calculated using:

225

$E_{\max }=\left(\mathrm{P}_{\mathrm{sk}, \mathrm{sat}}-\mathrm{P}_{\mathrm{a}}\right) /\left(\mathrm{R}_{\mathrm{e}, \mathrm{cl}}+\left[1 /\left(\mathrm{f}_{\mathrm{cl}} \cdot \mathrm{h}_{\mathrm{e}}\right)\right] \quad\left[\mathrm{W} / \mathrm{m}^{2}\right]\right.$

226 Where: $\mathrm{R}_{\mathrm{e}, \mathrm{cl}}$ is the evaporative heat transfer resistance of the clothing layer in $\mathrm{m}^{2} \mathrm{kPa} / \mathrm{W}, \mathrm{f}_{\mathrm{cl}}$ is the 227 clothing area factor (surface area of the clothed body divided by the surface area of the nude 228 body; ND), and $\mathrm{h}_{\mathrm{e}}$ is the evaporative heat transfer coefficient in $\mathrm{W} / \mathrm{m}^{2} / \mathrm{kPa}$. $\mathrm{P}_{\text {sk,sat }}-\mathrm{P}_{\mathrm{a}}$ is the 229 difference in water vapor pressure between the skin and air in $\mathrm{kPa}$. While $\mathrm{P}_{\mathrm{a}}$ is a measured in 230 absolute terms (in $\mathrm{kPa}), \mathrm{P}_{\mathrm{sk}, \mathrm{sat}}$ can be derived from Antoine's equation:

$231 P_{s k, s a t}=\left(\exp \left(18.956-\left[4030.18 /\left(\mathrm{T}_{\mathrm{sk}}+235\right)\right]\right)\right) / 10[\mathrm{kPa}]$ 
232 Where: $\mathrm{T}_{\mathrm{sk}}$ is mean skin temperature $\left({ }^{\circ} \mathrm{C}\right)$.

233 For equation 10 , the evaporative heat transfer coefficient $\left(\mathrm{h}_{\mathrm{e}}\right)$ in $\mathrm{W} / \mathrm{m}^{2} / \mathrm{kPa}$ can be estimated

234 using the product of the Lewis number (16.5 ND) and $\mathrm{h}_{\mathrm{c}}$ :

$235 h_{e}=16.5 h_{c}$

\section{Statistical Analysis}

237 Based on a power calculation $\left(\mathrm{G}^{*}\right.$ Power 3.1.9.2) with $\beta$ - and $\alpha$-values equal to 0.95 and 2380.05 respectively, a minimum sample size of 5 participants was required based on evidence from 239 critical vapor pressures of $4.16 \pm 0.19 \mathrm{kPa}$ and $4.60 \pm 0.13 \mathrm{kPa}$ for unacclimated (Kenney and 240 Zeman 2002) and heat acclimated (Kamon and Avellini 1976) women, respectively. All 241 thermometric, cardiovascular, and heat loss measurements were averaged over the last minute of 242 each humidity stage and expressed as means ( \pm standard deviation).

244 heart rate were observed was higher with fan use at both $36^{\circ} \mathrm{C}(\mathrm{F}: 4.9 \pm 0.4 \mathrm{kPa}, \mathrm{NF}: 3.7 \pm 0.5 \mathrm{kPa}$; $245 \mathrm{P}<0.001)$ and $42^{\circ} \mathrm{C}(\mathrm{F}: 3.8 \pm 0.6 \mathrm{kPa}, \mathrm{NF}: 3.1 \pm 0.6 ; \mathrm{P}=0.01)$. The temperature and humidity ranges

246 for stages during which an elevation in heart rate was observed are presented in Table 1. At the 247 stage corresponding to the upward rise in heart rate, paired t-tests were used to assess differences 248 between groups ( $36 \mathrm{~F}$ vs $36 \mathrm{NF}$; $42 \mathrm{~F}$ vs $42 \mathrm{NF}$ ) for $\mathrm{C}+\mathrm{R}, \mathrm{E}_{\text {req }}, \mathrm{E}_{\mathrm{max}}$, and $\omega_{\text {req. }}$. Moreover, paired t249 tests were used to assess the change from baseline to the end of the humidity ramp protocol 250 between fan conditions (i.e. $36 \mathrm{~F}$ vs $36 \mathrm{NF}$; $42 \mathrm{~F}$ vs $42 \mathrm{NF}$ ) for heart rate, and esophageal, rectal, 251 and mean skin temperatures. 
To compare physiological variables across humidity levels during which elevations in 253 heart rate were observed during the NF condition but not the F condition, three separate humidity 254 "zones" were identified for each participant (Figure 1) at $36^{\circ} \mathrm{C}$ and $42^{\circ} \mathrm{C}$. These zones were 255 defined as: Zone 1 (Z1): heart rate not elevated from baseline during both fan conditions; Zone 2 256 (Z2): heart rate elevated during NF, but not during the F condition; Zone 3 (Z3): heart rate 257 elevated during both fan conditions. A two-way repeated measures ANOVA was used to analyze 258 the data using the repeated factor of humidity "zone" (Rest, Z1, Z2, Z3, and End-Trial) and the 259 non-repeated factor of fan use (Levels: F and NF) to compare heart rate, skin, esophageal and 260 rectal temperatures, as well as local sweat rate and cutaneous vascular conductance. When

261 significance was found, individual differences were assessed using a Student's t-test. For all 262 multiple comparisons a fixed probability (5\%) of making a type I error was maintained 263 throughout using a Holm-Bonferroni correction. All analysis was conducted using Graphpad 264 Prism 6 for Windows statistical software (Version 6.01, La Jolla, CA, USA).

266 RESULTS

267 Alterations in human heat balance with fan use

268 At $36^{\circ} \mathrm{C}$, dry heat loss was greater with fan use $(\mathrm{P}=0.04)$, which led to a lower $\mathrm{E}_{\text {req }}$ 269 (Figure 2A). $E_{\max }$ at baseline was increased more than 2-fold during fan use compared to no fan $270(\mathrm{P}<0.01)$. During the subsequent step-wise increases in humidity, $\mathrm{E}_{\max }$ declined to a greater $271(\mathrm{P}<0.01)$ extent with fan use before an upward inflection in heart rate was observed (Figure 2A).

272 The $\omega_{\text {req }}$ at baseline was lower $(\mathrm{P}<0.001)$ with fan use $(0.13 \pm 0.02)$ compared to the no fan 273 condition $(0.28 \pm 0.04)$. At the critical humidity at which an upward inflection in heart rate was 274 observed, $\omega_{\text {req }}$ remained lower $(\mathrm{P}<0.01)$ with a fan $(0.38 \pm 0.13)$ than without a fan $(0.52 \pm 0.11)$. 
At $42^{\circ} \mathrm{C}$, dry heat gain was $\sim 70 \mathrm{~W} / \mathrm{m}^{2}$ greater $(\mathrm{P}<0.01)$ with fan use (Figure $\left.2 \mathrm{~B}\right)$, which

resulted in a greater $\mathrm{E}_{\text {req }}(\mathrm{P}<0.01)$. However, $\mathrm{E}_{\max }$ was 2-fold greater with fan use at baseline, and

277 declined a greater extent compared to the no fan condition $(\mathrm{P}<0.01)$ before an upward rise in 278 heart rate was observed (Figure 2B). At baseline, $\omega_{\text {req }}$ was lower $(\mathrm{P}<0.01)$ with fan use $279(0.35 \pm 0.02)$ compared to the no fan condition $(0.45 \pm 0.03)$. The $\omega_{\text {req }}$ at the critical humidity at 280 which an upward inflection in heart rate was observed was similar $(\mathrm{P}=0.34)$ with a fan $281(0.56 \pm 0.14)$ compared to the no fan condition $(0.61 \pm 0.07)$.

\section{Heart Rate}

The range of humidity which captured Z1, Z2, and Z3 is outlined in Tables 2 and 3 for

$28436^{\circ} \mathrm{C}$ and $42^{\circ} \mathrm{C}$, respectively. While $\mathrm{Z} 2$ demonstrates overlap in humidity due to individual 285 variability for the critical humidity at which an inflection in heart rate occurred, no overlap is 286 present between $\mathrm{Z} 1$ and $\mathrm{Z} 3$ for $36^{\circ} \mathrm{C}$ and $42^{\circ} \mathrm{C}$. Prior to beginning the humidity-ramp protocol, 287 heart rate was similar between conditions at $36^{\circ} \mathrm{C}(\mathrm{P}=0.60)$ and $42^{\circ} \mathrm{C}(\mathrm{P}=0.35)$. In humidity zone $2881(\mathrm{Z} 1)$, heart rate remained similar between conditions at both $36^{\circ} \mathrm{C}(P=0.27)$ and $42^{\circ} \mathrm{C}(P=$ 289 0.20). By definition, heart rate was greater during the no fan condition at both $36^{\circ} \mathrm{C}(P=0.002)$ 290 and $42^{\circ} \mathrm{C}(P=0.05)$ in $\mathrm{Z2}$. In $\mathrm{Z} 3$, heart rate was elevated from baseline during both conditions, 291 but was greater during the no fan condition at both $36^{\circ} \mathrm{C}(P=0.003)$ and $42^{\circ} \mathrm{C}(P=0.01)$. At the 292 end of the humidity-ramp protocol, heart rate was greater during the no fan condition at both $29336^{\circ} \mathrm{C}(P=0.02)$ and $42^{\circ} \mathrm{C}(P<0.001)$.

\section{Core and mean skin temperatures}

295 At $36^{\circ} \mathrm{C}$, esophageal and rectal temperatures were similar $(\mathrm{p}>0.05)$ between conditions at 296 baseline. Core temperatures were also similar between conditions across the 3 zones (Table 2). 297 At the end of the humidity-ramp protocol, esophageal temperature was greater without fan use 
$298(\mathrm{P}=0.01)$, but rectal temperature was similar $(\mathrm{P}=0.08)$ to when a fan was used (Table 2$).$ 299 Similarly, at $42^{\circ} \mathrm{C}$, esophageal and rectal temperatures were similar $(\mathrm{P}>0.05)$ between conditions

300 at baseline, and at each zone (Table 3). At the end of the humidity-ramp protocol, esophageal 301 temperature was greater without a fan $(\mathrm{P}=0.03)$, but rectal temperature was similar $(\mathrm{P}=0.21)$ 302 between conditions (Table 3 ).

303 At $36^{\circ} \mathrm{C}$, mean skin temperature was similar $(\mathrm{P}>0.05)$ between conditions at baseline, 304 heart rate zones 1 and 2 (Table 2), but became greater during the no fan condition during heart 305 rate zone $3(\mathrm{P}=0.01)$ and at the end of the humidity-ramp protocol $(\mathrm{P}=0.007)$. At $42^{\circ} \mathrm{C}$, mean 306 skin temperature was greater $(\mathrm{P}<0.05)$ with fan use at baseline, and during all three zones $($ Table 307 3). By the end of the humidity-ramp protocol, mean skin temperature was similar between 308 conditions $(\mathrm{P}=0.14)$ due to a greater $(\mathrm{P}=0.04)$ increase in mean skin temperature from baseline 309 during the no fan condition (Table 3).

310 Mean Arterial Pressure

311 Mean arterial pressure was similar $(\mathrm{P}>0.05)$ between conditions throughout the humidity312 ramp protocol at both $36^{\circ} \mathrm{C}$ (Table 2$)$ and $42^{\circ} \mathrm{C}$ (Table 3$)$.

\section{$313 \quad$ Sweating}

314 At $36^{\circ} \mathrm{C}$, local sweat rate was similar between conditions at baseline and during Z1, but 315 was greater $(\mathrm{P}<0.05)$ without fan use during $\mathrm{Z} 2$ and $\mathrm{Z3}$, as well as at the end of the humidity316 ramp protocol (Table 2). At $42^{\circ} \mathrm{C}$, local sweat rate was also similar between conditions at 317 baseline and during $\mathrm{Z} 1$, but became greater $(\mathrm{P}<0.05)$ without fan use during $\mathrm{Z} 2$ and $\mathrm{Z} 3$ as well as 318 at the end of the humidity-ramp protocol (Table 3). As previously reported (Ravanelli et al. $3192015)$, whole body sweat rate was greater at $36^{\circ} \mathrm{C}$ with a fan $(180 \pm 10 \mathrm{~g} / \mathrm{hr})$ than without $(153 \pm 18$ 
$320 \mathrm{~g} / \mathrm{hr} ; \mathrm{P}=0.01)$. Similarly at $42^{\circ} \mathrm{C}$, whole body sweat rate was greater with a fan $(399 \pm 26 \mathrm{~g} / \mathrm{hr})$

321 than without $(241 \pm 46 \mathrm{~g} / \mathrm{hr} ; \mathrm{P}<0.001)$.

322 Skin blood flow

323 At $36^{\circ} \mathrm{C}$, skin blood flow (absolute values) and cutaneous vascular conductance were

324 similar between conditions at baseline and during $\mathrm{Z} 1$ and $\mathrm{Z} 2$, but became greater without a fan

325 during $\mathrm{Z} 3$ and at the end of the protocol (Table 2). At $42^{\circ} \mathrm{C}$, skin blood flow (absolute units) and

326 cutaneous vascular conductance was similar between conditions throughout the humidity-ramp

327 protocol (Table 3).

\section{DISCUSSION}

329 The current study examined potential biophysical and physiological factors associated

330 with the delayed increase in heart rate with fan use during extreme heat and humidity conditions.

331 Biophysically, a greater air velocity across the skin surface with fan use led to negligible changes

332 in dry heat exchange at $36^{\circ} \mathrm{C}$, whereas $\sim 70 \mathrm{~W} / \mathrm{m}^{2}$ of additional dry heat was gained via

333 convection at $42^{\circ} \mathrm{C}$ (Figure 2). However, at both ambient temperatures the greater potential for

334 evaporation with fan use increased evaporative efficiency. While evaporative efficiency was not

335 directly quantified, the additional $\sim 70 \mathrm{~W} / \mathrm{m}^{2}$ of dry heat gain with fan use at $42^{\circ} \mathrm{C}$ must have

336 been offset by at least an equally greater evaporative heat loss as the increase in core temperature

337 was delayed relative to the no fan condition (Ravanelli et al. 2015). From a physiological

338 perspective, the different inflection points for increases in heart rate between the fan and no fan

339 conditions seemed to coincide with elevations in sudomotor output at both $36^{\circ} \mathrm{C}$ and $42^{\circ} \mathrm{C}$.

340 Collectively, the delayed increase in heart rate with electric fan use was associated with 341 increased evaporative efficiency and lower sudomotor output. 
At $36^{\circ} \mathrm{C}$, air temperature was similar to mean skin temperature. Therefore, differences in

343 dry heat loss and thus the evaporative requirement for heat balance were trivial $\left(<5 \mathrm{~W} / \mathrm{m}^{2}\right)$

344 between conditions. The influence of fan use on the potential for evaporative heat loss however 345 was profound (i.e. $\sim 250 \mathrm{~W} / \mathrm{m}^{2}$ greater with a fan; Figure $2 \mathrm{~A}$ ) due to a greater convective and 346 therefore evaporative heat transfer coefficient (Nelson et al. 1948; Clifford et al. 1959). As 347 ambient humidity progressively increased during the humidity-ramp protocol, $\mathrm{E}_{\max }$ naturally 348 declined due to a shrinking humidity gradient between the skin and air. The $\mathrm{E}_{\max }$ value at which 349 elevations in heart rate occurred was slightly greater with fan use. However, because $\mathrm{E}_{\max }$ started 350 at a much greater level with fan use it look longer, and therefore a greater relative humidity (i.e. $35183 \pm 6 \% \mathrm{RH}$; Ravanelli et al. 2015), for $\mathrm{E}_{\max }$ to reach a similar level as that observed during the no 352 fan condition. This greater "buffer" for increases in humidity with fan use at $36^{\circ} \mathrm{C}$ can be 353 explained in terms of greater evaporative efficiency. The work of Candas et al. (1979ab) and 354 Alber-Wallstrom et al. (1985) demonstrate that if $\mathrm{E}_{\mathrm{req}}$ is small relative to $\mathrm{E}_{\max }$, evaporative 355 efficiency is greater, but as $\mathrm{E}_{\mathrm{req}}$ approaches $\mathrm{E}_{\max }$ evaporative efficiency rapidly declines. Prior to 356 the start of the humidity ramp protocol at $36^{\circ} \mathrm{C}, \mathrm{E}_{\text {req }}$ was $\sim 10 \%$ of $\mathrm{E}_{\max }$ with fan use but $\sim 30 \%$ of $357 \mathrm{E}_{\max }$ without fan use (Figure 2A). Decrements in evaporative efficiency would have therefore 358 occurred at a lower relative humidity (i.e. earlier during the ramp protocol) during the no fan 359 condition. In order to maintain heat balance during heat stress, $\mathrm{E}_{\text {req }}$ must be sustained. With 360 reductions in evaporative efficiency, a concomitant rise in sweating must occur to sustain $\mathrm{E}_{\text {req }}$ 361 which was reflected by greater local sweat rate values (Table 2).

362 The main argument proposed by public health agencies for not using a fan during heat 363 waves is that additional air flow across the skin will accelerate dry heat gain (Wolfe 2003; CDC 364 2004; WHO 2009). Indeed, this was observed during the $42^{\circ} \mathrm{C}$ trial as fan use resulted in $\sim 70$ 
$365 \mathrm{~W} / \mathrm{m}^{2}$ greater dry heat gain. However, an often-neglected advantage of fan use in the public 366 health literature is that it also promotes evaporation by increasing evaporative efficiency. In this

367 study, fan use resulted in an evaporative heat loss potential that was $160 \mathrm{~W} / \mathrm{m}^{2}$ greater relative to 368 no fan use. As such, the required evaporation for heat balance only accounted for $\sim 35 \%$ of the 369 maximum evaporative potential during fan use, relative to $\sim 45 \%$ with no fan. According to the 370 findings of Alber-Wallstrom et al. (1985), decrements in evaporative efficiency would have 371 occurred even before the humidity ramp protocol started during the no-fan condition, whereas 372 fan use would have maintained sweat evaporation at $\sim 100 \%$. Moreover, the critical skin 373 wettedness $\left(\omega_{\text {crit }} ; \mathrm{E}_{\text {req }} / \mathrm{E}_{\max }\right)$ at which elevations in heart rate were observed by Berglund and 374 Gonzalez (1977) was lower with air movement relative to still air. The present results partially 375 concur with these findings with lower $\omega_{\text {crit }}$ when the inflection in heart rate occurred at $36^{\circ} \mathrm{C}(\mathrm{F}$ :

$3760.38 \pm 0.13$; NF: $0.52 \pm 0.11)$, but not $42^{\circ} \mathrm{C}(\mathrm{F}: 0.56 \pm 0.14 ; \mathrm{NF}: 0.61 \pm 0.07)$. The reason for 377 differences in $\omega_{\text {crit }}$ between fan conditions at $36^{\circ} \mathrm{C}$ but not $42^{\circ} \mathrm{C}$ is unclear, however it must be 378 acknowledged that partitional calorimetric estimates of heat transfer values are based on several 379 assumptions and subject to variability. Despite these limitations, we propose that fan use 380 facilitated a greater evaporative efficiency during the humidity-ramp protocol, which is further 381 supported by the lower local sweat rate values (Table 3 ).

382 The underlying physiological mechanisms responsible for the delayed increase in heart 383 rate with fan use are difficult to determine from the present data. It was hypothesized that earlier 384 heart rate elevations without fan use would be preceded by greater peripheral vasodilation, 385 leading to a greater heart rate requirement for the maintenance of blood pressure. Indirect 386 evidence suggests this may be the case. Assuming stroke volume was similar between fan and no 387 fan conditions, greater heart rate during the no fan conditions presumably lead to greater cardiac 
output. Given that blood pressure was similar between fan and no fan conditions, it is possible that a greater cardiac output would be associated with greater peripheral vasodilation during the no fan conditions. In theory, this could be due to greater cutaneous vasodilation, although we

391 cannot rule out the possibility of greater vasodilation within other vascular beds. While this

392 hypothesis is supported by greater cutaneous vasodilation during the no fan condition when

393 elevations in heart rate were observed at $36^{\circ} \mathrm{C}$, a separation in heart rate between fan conditions

394 (Z2) was observed without any preceding differences in cutaneous vasodilation at $42^{\circ} \mathrm{C}$ (Table

395 3). Alternatively, a higher mean skin temperature at $42^{\circ} \mathrm{C}$ with fan use could have theoretically

396 led to greater cutaneous vasodilation (Rowell et al. 1970; Wyss et al. 1975; Wingo et al. 2010)

397 and heart rate via stimulation of cutaneous thermoreceptors (Shibasaki et al. 2015); but this was

398 not observed. In fact, heart rate was lower with fan use at $42^{\circ} \mathrm{C}$.

399 It should be noted that cutaneous vasodilation was only measured at two local sites and it

400 is therefore possible that differences in other body regions were not detected. Rowell et al. 401 (1970) reported that elevations in heart rate during aggressive passive heating $\left(47.5^{\circ} \mathrm{C}\right.$ water 402 perfused suit) were not lowered following the restoration of mean arterial pressure to 403 normothermic levels, suggesting that blood pressure maintenance is not necessarily the primary 404 driver of heat-related elevations in heart rate. This notion was further supported by Cui et al. 405 (2002) who observed only a minor decrease in heart rate during passive heating $\left(46^{\circ} \mathrm{C}\right.$ water 406 perfused suit) following the reestablishment of normothermic blood pressure with phenylephrine 407 infusion. Collectively, these and other studies (Kamon and Belding 1971; Wyss et al. 1974; 408 Gorman and Proppe 1982) suggest that heart rate elevations during passive heating are partially 409 driven by direct effects of temperature upon the heart (Jose et al. 1970; Gorman and Proppe 410 1982). However, core temperatures were similar between fan and no fan conditions, and were 
411 actually unchanged from baseline when the elevations in heart rate occurred at both ambient

412 temperatures. Differences in core temperature therefore cannot explain the earlier elevations in

413 heart rate observed without fan use. The only physiological response measured that differed

414 between fan conditions at both ambient temperatures when the elevation in heart rate occurred

415 without fan use was local sweat rate (Table $2 \& 3$ ).

\section{Perspectives}

417 The present results suggest that the different critical humidities at which elevations in

418 heart rate are observed with and without fan use are potentially associated with an elevated

419 sudomotor drive, secondary to decrements in evaporative efficiency. While future studies are 420 required to examine whether this is a direct cause-and-effect or indirect link, cooling

421 interventions during extreme heat exposure (i.e. heat waves) that strive to mitigate elevations in 422 heart rate could possibly focus on reducing the heat balance requirement for sweat production.

423 Under circumstances that air conditioning is not available, which is commonplace for most 424 vulnerable populations during heat waves (Bouchama et al. 2007; Basu and Ostro 2008; 425 Kravchenko et al. 2013), the propagation of convective flow across the skin coupled with 426 external moistening of the skin may suppress the need for sweating. Empirical evidence 427 supporting this notion however is needed. If supplemental air flow is not available, a 428 combination of external skin wetting and conductive cooling (e.g. cold water forearm or foot 429 immersion) that provides $\sim 80-90 \mathrm{~W} / \mathrm{m}^{2}$ of heat loss would minimize the evaporative requirement 430 for heat balance and therefore reduce the necessity for sweating at $42^{\circ} \mathrm{C}$ (Figure $2 \mathrm{~B}$ ).

\section{$431 \quad$ Limitations and Future Studies}

432 The present data pertain only to young, healthy males; they therefore do not account for 433 age-related decrements in sweating capacity of older individuals (Kenney and Hodgson 1987; 
434 Inoue et al. 1991), nor the lower maximum evaporative capacity of females (Gagnon and Kenny

435 2011). The potential benefit of fan use has also only been demonstrated in hot/humid conditions.

436 Inhabitants of some geographical regions (e.g. South Australia) often experience very hot

$437\left(>45^{\circ} \mathrm{C}\right)$ and dry $(\mathrm{RH}<10 \%)$ heat waves. In such environments, most secreted sweat would

438 readily evaporate in relatively still air and fan use may therefore not increase evaporative

439 efficiency while creating additional dry heat gain. The efficacy of fan use under hot/dry versus

440 hot/humid conditions must therefore be evaluated. Moreover, metabolic heat production was not

441 measured directly and assumed to be constant. While this assumption may be limited, Hardy \&

442 Stolwijk (1966) observed very minor differences in metabolic rate between the ambient

443 temperatures tested in the present study. It is also difficult to provide a comprehensive 444 explanation for the different heart rate responses between fan conditions without measurements 445 of cardiac output, therefore further research incorporating this measure is warranted. Finally, 446 only one fan speed, diameter, orientation and distance from the participant was tested and further 447 research is required to assess the influence of these variables on thermal and cardiovascular 448 strain.

\section{Conclusion}

450 In conclusion, delayed elevations in heart rate with fan use during extreme heat and 451 humidity conditions are associated with i) a greater increase in evaporative efficiency relative to 452 the increase in convective heat gain; and ii) a lower sudomotor output.

\section{ACKNOWLEDGEMENTS}

455 The authors thank the volunteers for their participation in the present study. 


\section{GRANTS}

458 This research was supported by the Natural Sciences and Engineering Research Council of

459 Canada (NSERC) Discovery Grant (no.386143-2010, O. Jay). N.M. Ravanelli is supported by a 460 University of Ottawa Excellence Scholarship and a NSERC Postgraduate Scholarship (PGS-D).

\section{AUTHOR CONTRIBUTIONS}

463 N.M.R., O.J., S.H., \& G.H. were involved in the concept and design of the research question and 464 methodology; N.M.R. performed all data collection; N.M.R. analyzed the data; N.M.R., O.J., 465 S.H., G.H., \& D.G. interpreted the results; N.M.R. prepared figures; N.M.R. \& O.J. drafted the 466 manuscript; N.M.R. \& O.J. edited the manuscript; N.M.R., O.J., D.G., S.H., \& G.H. approved 467 the final version of manuscript.

\section{DISCLOSURES}

470 No conflicts of interest, financial or otherwise, are declared by any of the authors.

472 Ethical approval: All procedures performed in studies involving human participants were in

473 accordance with the ethical standards of the institutional and/or national research committee and 474 with the 1964 Helsinki declaration and its later amendments or comparable ethical standards. 


\section{REFERENCES}

476

Adams WC, Mack GW, Langhans GW, Nadel ER (1992) Effects of varied air velocity on sweating and evaporative rates during exercise. J Appl Physiol 73:2668-2674.

Alber-Wallerström B (1985) Efficiency of sweat evaporation in unacclimatized man working in a hot humid environment. Eur J Appl Physiol 54:480-487.

Basu R, Ostro BD (2008) A multicounty analysis identifying the populations vulnerable to mortality associated with high ambient temperature in california. Am J Epidemiol 168:632-637. doi: 10.1093/aje/kwn170

Berglund LG, Gonzalez RR (1977) Evaporation of sweat from sedentary man in humid environments. J Appl Physiol 42:767-772.

Bouchama A, Dehbi M, Mohamed G, et al (2007) Prognostic factors in heat wave-related deaths: A meta-analysis. Arch Intern Med 167:2170-2176. doi: 10.1001/archinte.167.20.ira70009

Candas V, Libert JP, Vogt JJ (1979b) Influence of air velocity and heat acclimation on human skin wettedness and sweating efficiency. J Appl Physiol 47:1194-1200.

Candas V, Libert JP, Vogt JJ (1979a) Human skin wettedness and evaporative efficiency of sweating. J Appl Physiol 46:522-528.

CDC (2004) Extreme heat: a prevention guide to promote your personal health and safety. http://www.bt.cdc.gov/disasters/extremeheat/heat_guide.asp. Accessed 2 Apr 2013

Clifford J, Kerslake DM, Waddell JL (1959) The effect of wind speed on maximum evaporative capacity in man. J Physiol 147:253-259.

Cui J, Wilson TE, Crandall CG (2002) Phenylephrine-induced elevations in arterial blood pressure are attenuated in heat-stressed humans. Am J Physiol - Regul Integr Comp Physiol 283:R1221-R1226. doi: 10.1152/ajpregu.00195.2002

DuBois D, Dubois E (1916) A formula to estimate surface area if height and weight are known. Arch Intern Med 17:863.

Fanger PO (1967) Calculation of thermal comfort: introduction of a basic comfort equation.

Fouillet A, Rey G, Laurent F, et al (2006) Excess mortality related to the August 2003 heat wave in France. Int Arch Occup Environ Health 80:16-24. doi: 10.1007/s00420-006-0089-4

Gagge AP (1937) A new physiological variable associated with sensible and insensible perspiration. Am J Physiol -- Leg Content 120:277-287.

Gagge AP, Herrington LP, Winslow C-EA (1937) Thermal interchanges between the human body and Its atmospheric environment. Am J Epidemiol 26:84-102. 
Gagnon D, Kenny GP (2011) Sex modulates whole-body sudomotor thermosensitivity during exercise. J Physiol 589:6205-6217. doi: 10.1113/jphysiol.2011.219220

Gorman AJ, Proppe DW (1982) Influence of heat stress on arterial baroreflex control of heart rate in the baboon. Circ Res 51:73-82. doi: 10.1161/01.RES.51.1.73

Gupta S, Carmichael C, Simpson C, et al (2012) Electric fans for reducing adverse health impacts in heatwaves. In: Cochrane Database of Systematic Reviews. John Wiley \& Sons, Ltd,

Hajat S, O'Connor M, Kosatsky T (2010) Health effects of hot weather: from awareness of risk factors to effective health protection. The Lancet 375:856-863. doi: 10.1016/S01406736(09)61711-6

Hardy JD, Stolwijk JA (1966) Partitional calorimetric studies of man during exposures to thermal transients. Journal of Applied Physiology 21:1799-1806.

Hartz DA, Golden JS, Sister C, et al (2012) Climate and heat-related emergencies in Chicago, Illinois (2003-2006). Int J Biometeorol 56:71-83. doi: 10.1007/s00484-010-0398-x

Inoue Y, Nakao M, Araki T, Murakami H (1991) Regional differences in the sweating responses of older and younger men. J Appl Physiol 71:2453-2459.

Jose AD, Stitt F, Collison D (1970) The effects of exercise and changes in body temperature on the intrinsic heart rate in man. Am Heart J 79:488-498. doi: 10.1016/00028703(70)90254-1

Kamon E, Avellini B (1976) Physiologic limits to work in the heat and evaporative coefficient for women. J Appl Physiol 41:71-76.

Kamon E, Belding HS (1971) Heart rate and rectal temperature relationships during work in hot humid environments. J Appl Physiol 31:472-477.

Kenefick RW, Cheuvront SN (2012) Hydration for recreational sport and physical activity. Nutr Rev 70:S137-S142. doi: 10.1111/j.1753-4887.2012.00523.x

Kenney WL, Hodgson JL (1987) Heat tolerance, thermoregulation and ageing. Sports Med 4:446-456. doi: 10.2165/00007256-198704060-00004

Kenney WL, Mikita DJ, Havenith G, et al (1993) Simultaneous derivation of clothing-specific heat exchange coefficients. Med Sci Sports Exerc 25:283-289.

Kenney WL, Zeman MJ (2002) Psychrometric limits and critical evaporative coefficients for unacclimated men and women. J Appl Physiol 92:2256-2263. doi:

10.1152/japplphysiol.01040.2001

Kerslake DM (1972) The Stress of Hot Environments. Cambridge: Cambridge University Press 
Kravchenko J, Abernethy AP, Fawzy M, Lyerly HK (2013) Minimization of Heatwave Morbidity and Mortality. Am J Prev Med 44:274-282. doi:

10.1016/j.amepre.2012.11.015

Lancet T (2015) Health professionals: be prepared for heatwaves. The Lancet 386:219. doi: $10.1016 / \mathrm{S} 0140-6736(15) 61261-2$

Luber G, McGeehin M (2008) Climate change and extreme heat events. Am J Prev Med 35:429435. doi: 10.1016/j.amepre.2008.08.021

Matthies F, Bickler G, Marin N, Hales S (2008) Heat-Health Action Plans. World Health Organization, Europe

Mekjavic IB, Rempel ME (1990) Determination of esophageal probe insertion length based on standing and sitting height. J Appl Physiol 69:376-379.

Mitchell D (1974) Convective heat loss from man and other animals. In: Monteith JL, Mount LE, editors. Heat Loss from Animals and Man. London: Butterworths.

Nelson NA, Shelley WB, Horvath SM, et al (1948) The influence of clothing, work, and air movement on the thermal exchanges of acclimatized men in various hot environments. $\mathrm{J}$ Clin Invest 27:209-216. doi: 10.1172/JCI101935

Nitschke M, Tucker GR, Hansen AL, et al (2011) Impact of two recent extreme heat episodes on morbidity and mortality in Adelaide, South Australia: a case-series analysis. Environ Health 10:42. doi: 10.1186/1476-069X-10-42

Parsons K (2002) Human Thermal Environments: The Effects of Hot, Moderate, and Cold Environments on Human Health, Comfort and Performance, Second Edition. CRC Press

Ramanathan NL (1964) A new weighting system for mean surface temperature of the human body. J Appl Physiol 19:531-533.

Ravanelli NM, Havenith G, Hodder S, Jay O (2015) Heart rate and body temperature responses to extreme heat and humidity with and without electric fans. J Am Med Assoc 313:724 725.

Rowell LB, Brengelmann GL, Blackmon JR, Murray JA (1970) Redistribution of blood flow during sustained high skin temperature in resting man. J Appl Physiol 28:415-420.

Salamanca F, Georgescu M, Mahalov A, et al (2014) Anthropogenic heating of the urban environment due to air conditioning. J Geophys Res Atmospheres 2013JD021225. doi: 10.1002/2013JD021225

Schuman SH (1972) Patterns of urban heat-wave deaths and implications for prevention: Data from New York and St. Louis during July, 1966. Environ Res 5:59-75. doi: 10.1016/0013-9351(72)90020-5 
Shibasaki M, Umemoto Y, Kinoshita T, et al (2015) The role of cardiac sympathetic innervation and skin thermoreceptors on cardiac responses during heat stress. American Journal of Physiology - Heart and Circulatory Physiology 308:H1336-H1342.

Smith CJ, Kenney WL, Alexander LM (2013) Regional relation between skin blood flow and sweating to passive heating and local administration of acetylcholine in young, healthy humans. Am J Physiol - Regul Integr Comp Physiol 304:R566-R573. doi: 10.1152/ajpregu.00514.2012

Victorian Government Department of Health (2013) Residential aged care services heatwave ready resource. Ageing and Aged Care, Melbourne, Australia

Whitman S, Good G, Donoghue ER, et al (1997) Mortality in Chicago attributed to the July 1995 heat wave. Am J Public Health 87:1515-1518.

WHO (2009) Improving public health responses to extreme weather/heat-waves - EuroHEAT.

Wingo JE, Low DA, Keller DM, et al (2010) Skin blood flow and local temperature independently modify sweat rate during passive heat stress in humans. J Appl Physiol 109:1301-1306. doi: 10.1152/japplphysiol.00646.2010

Wolfe RM (2003) Death in heat waves: beware of fans. Br Med J Int Ed 327:1228.

Wyss CR, Brengelmann GL, Johnson JM, et al (1975) Altered control of skin blood flow at high skin and core temperatures. J Appl Physiol 38:839-845.

Wyss CR, Brengelmann GL, Johnson JM, et al (1974) Control of skin blood flow, sweating, and heart rate: role of skin vs. core temperature. J Appl Physiol 36:726-733. 
Table 1 Ambient temperature $\left(\mathrm{T}_{\mathrm{a}}\right)$ and absolute humidity $(\mathrm{AH})$ for each stepwise increase in humidity at $36^{\circ} \mathrm{C}$ and $42^{\circ} \mathrm{C}$ expressed as mean \pm standard deviation. Shaded rows denote the stages coinciding with an upward rise in heart rate.

\begin{tabular}{c|cccc|cccc} 
& \multicolumn{3}{|c}{$\mathbf{3 6}^{\circ} \mathbf{C}-\mathbf{F a n}$} & \multicolumn{2}{c}{$\mathbf{3 6}^{\circ} \mathbf{C}-\mathbf{N o} \mathbf{f a n}$} & \multicolumn{2}{c}{$\mathbf{4 2}^{\circ} \mathbf{C}-\mathbf{F a n}$} & \multicolumn{2}{c}{$\mathbf{4 2}^{\circ} \mathbf{C}-\mathbf{N o}$ fan } \\
& $\mathbf{T}_{\mathbf{a}}\left({ }^{\circ} \mathbf{C}\right)$ & $\mathbf{A H}(\mathbf{k P a})$ & $\mathbf{T}_{\mathbf{a}}\left({ }^{\circ} \mathbf{C}\right)$ & $\mathbf{A H}(\mathbf{k P a})$ & $\mathbf{T}_{\mathbf{a}}\left({ }^{\circ} \mathbf{C}\right)$ & $\mathbf{A H} \mathbf{( k P a})$ & $\mathbf{T}_{\mathbf{a}}\left({ }^{\circ} \mathbf{C}\right)$ & $\mathbf{A H} \mathbf{( k P a})$ \\
\hline $\mathbf{1}$ & $36.6 \pm 0.2$ & $1.7 \pm 0.2$ & $36.2 \pm 0.3$ & $1.7 \pm 0.1$ & $42.8 \pm 0.1$ & $1.8 \pm 0.1$ & $41.3 \pm 0.4$ & $1.9 \pm 0.1$ \\
$\mathbf{2}$ & $36.7 \pm 0.3$ & $2.0 \pm 0.0$ & $36.3 \pm 0.3$ & $2.0 \pm 0.0$ & $42.8 \pm 0.1$ & $2.0 \pm 0.1$ & $41.4 \pm 0.3$ & $2.0 \pm 0.1$ \\
$\mathbf{3}$ & $36.6 \pm 0.4$ & $2.4 \pm 0.1$ & $36.4 \pm 0.2$ & $2.4 \pm 0.1$ & $42.8 \pm 0.1$ & $2.3 \pm 0.2$ & $41.5 \pm 0.3$ & $2.3 \pm 0.2$ \\
$\mathbf{4}$ & $36.6 \pm 0.4$ & $2.7 \pm 0.1$ & $36.4 \pm 0.3$ & $2.7 \pm 0.1$ & $42.8 \pm 0.1$ & $2.6 \pm 0.3$ & $41.5 \pm 0.3$ & $2.5 \pm 0.3$ \\
$\mathbf{5}$ & $36.6 \pm 0.4$ & $3.0 \pm 0.1$ & $36.4 \pm 0.2$ & $3.0 \pm 0.1$ & $42.8 \pm 0.0$ & $2.9 \pm 0.1$ & $41.6 \pm 0.2$ & $2.9 \pm 0.2$ \\
$\mathbf{6}$ & $36.6 \pm 0.4$ & $3.3 \pm 0.0$ & $36.5 \pm 0.3$ & $3.3 \pm 0.1$ & $42.8 \pm 0.1$ & $3.2 \pm 0.1$ & $41.6 \pm 0.2$ & $3.3 \pm 0.1$ \\
$\mathbf{7}$ & $36.6 \pm 0.4$ & $3.5 \pm 0.0$ & $36.5 \pm 0.3$ & $3.5 \pm 0.1$ & $42.8 \pm 0.1$ & $3.4 \pm 0.1$ & $41.6 \pm 0.2$ & $3.5 \pm 0.1$ \\
$\mathbf{8}$ & $36.7 \pm 0.3$ & $3.8 \pm 0.0$ & $36.6 \pm 0.2$ & $3.8 \pm 0.0$ & $42.8 \pm 0.1$ & $3.7 \pm 0.1$ & $41.6 \pm 0.2$ & $3.7 \pm 0.1$ \\
$\mathbf{9}$ & $36.7 \pm 0.3$ & $4.1 \pm 0.0$ & $36.6 \pm 0.2$ & $4.1 \pm 0.0$ & $42.8 \pm 0.1$ & $3.9 \pm 0.1$ & $41.6 \pm 0.2$ & $4.0 \pm 0.1$ \\
$\mathbf{1 0}$ & $36.7 \pm 0.3$ & $4.4 \pm 0.0$ & $36.6 \pm 0.2$ & $4.4 \pm 0.1$ & $42.8 \pm 0.1$ & $4.1 \pm 0.0$ & $41.7 \pm 0.3$ & $4.2 \pm 0.1$ \\
$\mathbf{1 1}$ & $36.7 \pm 0.3$ & $4.6 \pm 0.0$ & $36.7 \pm 0.2$ & $4.7 \pm 0.1$ & $42.8 \pm 0.1$ & $4.3 \pm 0.0$ & $41.6 \pm 0.3$ & $4.4 \pm 0.1$ \\
$\mathbf{1 2}$ & $36.7 \pm 0.2$ & $4.9 \pm 0.0$ & $36.7 \pm 0.2$ & $5.0 \pm 0.1$ & $42.8 \pm 0.1$ & $4.6 \pm 0.1$ & $41.7 \pm 0.3$ & $4.7 \pm 0.1$ \\
$\mathbf{1 3}$ & $36.7 \pm 0.2$ & $5.2 \pm 0.1$ & $36.7 \pm 0.2$ & $5.2 \pm 0.1$ & $42.8 \pm 0.1$ & $4.8 \pm 0.0$ & $41.7 \pm 0.3$ & $4.9 \pm 0.1$ \\
$\mathbf{1 4}$ & $36.7 \pm 0.2$ & $5.4 \pm 0.1$ & $36.8 \pm 0.2$ & $5.4 \pm 0.1$ & $42.8 \pm 0.1$ & $5.1 \pm 0.1$ & $41.8 \pm 0.3$ & $5.2 \pm 0.1$ \\
$\mathbf{1 5}$ & $36.7 \pm 0.2$ & $5.6 \pm 0.1$ & $36.8 \pm 0.2$ & $5.6 \pm 0.1$ & $42.8 \pm 0.1$ & $5.3 \pm 0.0$ & $41.7 \pm 0.3$ & $5.4 \pm 0.1$ \\
$\mathbf{1 6}$ & $36.7 \pm 0.2$ & $5.6 \pm 0.2$ & $36.9 \pm 0.2$ & $5.7 \pm 0.1$ & $42.7 \pm 0.1$ & $5.6 \pm 0.1$ & $41.7 \pm 0.4$ & $5.6 \pm 0.1$
\end{tabular}

